\title{
Antimicrobial Resistance of Shiga Toxin-Producing Escherichia coli Causing Human Illness
}

\author{
Liora COLOBĂŢIU ${ }^{1}$, Alexandra TĂBĂRAN ${ }^{2}$, Simona MIREL ${ }^{1}$, Marian MIHAIU², Ovidiu ONIGA ${ }^{1}$ \\ 1) Department of Medical Devices, Iuliu Hatieganu University of Medicine and Pharmacy,Cluj-Napoca, \\ Romania; liora30@yahoo.com \\ ${ }^{2)}$ Department of Animal Breeding and Food Safety, University of Agricultural Sciences and Veterinary \\ Medicine, Cluj-Napoca, Romania; m.mihaiufmv@yahoo.com \\ *Corresponding author e-mail: liora30@yahoo.com
}

Bulletin UASVM Veterinary Medicine 71(2) / 2014,

Print ISSN 1843-5270; Electronic ISSN 1843-5378

DOI:10.15835/buasvmcn-vm: 10628

\begin{abstract}
Escherichia coli is usually a commensal bacterium of humans and animals. Pathogenic variants cause intestinal and extra intestinal infections, including gastroenteritis, urinary tract infection, meningitis, peritonitis and septicemia. Nowadays, the worldwide concern on the spread of this bacterium is mainly connected to the resistance phenomenon. This research was conducted in order to reveal antimicrobial resistance patterns in Escherichia coli, causing human illness.

A total of 30 Escherichia coli isolates were recovered from patients hospitalized with food-borne infections, during June 2013-May 2014. The majority of the patients declared the consumption of undercooked meat products (especially beef), raw milk and soft cheeses. The isolates were tested through polymerase chain reaction (PCR) for identification and confirmation of pathogenicity and further, for antimicrobial susceptibility to 26 antimicrobials, using the classical disk diffusion method.

All isolates were Shiga Toxin-producing Escherichia coli (STEC). All isolates proved to be resistant to at least one antimicrobial agent. Resistance was most frequently observed to ampicillin, amoxicillin and clavulanic acid, ceftazidime, cefepime and norfloxacin.

Our findings demonstrate that Shiga Toxin-producing Escherichia coli recovered from hospitalized patients and presumably of animal origin is highly resistant to critically important antimicrobials for human medicine. These data support the ongoing concern regarding antimicrobial resistance, antimicrobial use in veterinary and human medicine and nevertheless, the problem of antimicrobial resistance in the food chain.
\end{abstract}

Keywords: antimicrobial resistance, Escherichia coli, food safety, human illness;

\section{INTRODUCTION}

Escherichia coli (E.coli) are the most prevalent bacteria in animals and humans and are also an important zoonotic agent, which can be implicated in animal and human infectious diseases (Costa et al., 2008). In humans, E.coli can cause a variety of intestinal and extra-intestinal infections, such as diarrhea, urinary tract infection, meningitis, peritonitis, septicemia and gram-negative bacterial pneumonia (Hammerum and Heuer, 2013).

Based on virulence properties, enteric E.coli are classified into enterotoxigenic (ETEC), enteropathogenic (EPEC), enteroinvasive (EIEC), verotoxigenic or Shiga toxin-producing E.coli (VTEC or STEC), enterohemorrhagic (EHEC) and enteroaggregative (EAEC), all being causative agents of diarrhea.

STEC represents a major cause of gastroenteritis that may be complicated by haemorrhagic colitis, or the hemolytic-uremic syndrome, which is the main cause of acute renal failure in children (Mora et al., 2005).

E.coli 0157:H7, which belongs to STEC group is the most common serotype isolated from individuals with haemorrhagic colitis. Outbreaks of infection with those bacteria have emerged 
due to the consumption of contaminated animalderived food products (Belongia et al., 1991).

Contaminated food, especially undercooked ground beef, unpasteurized (raw) milk, soft cheeses made of raw milk and even raw fruits and vegetables (such as sprouts) are considered important sources of E.coli infection.

Meat and meat products can be easily contaminated by E.coli during animal evisceration after slaughter, through contact with tainted water or during meat handling (Alvarez-Fernandez et al., 2013).

Antimicrobial agents are widely used not only in human medicine but also in food animal production; therefore, meat is frequently contaminated with antimicrobial resistant bacteria, including E.coli.

Humans can be colonized with E.coli of animal origins, and because of resistance to commonly used antimicrobial agents, these bacteria may cause infections for which limited therapeutic options are available (Hammerum and Heuer, 2013).

Furthermore, foods contaminated with antibiotic resistant bacteria could be a major threat to public health, as there is the distinct possibility that genes encoding antibiotic resistance determinants that are carried on mobile genetic elements may be transferred to other bacteria of human clinical significance (Van et al., 2008).

In Romania, like in many other developing countries, antimicrobial resistance epidemiology is still in development and little is known about the potential role of contaminated food (especially meat and meat products) in the dissemination of multidrug-resistant E.coli, because very limited research works had been carried out in our country concerning these aspects.

This study was conducted in order to reveal antimicrobial resistance patterns of E.coli of presumably animal origin, causing human illness.

\section{MATERIALS AND METHODS}

A total of 30 E.coli isolates recovered from patients hospitalized with food-borne infections at the Hospital of Infectious Diseases from ClujNapoca, between June 2013-May 2014 were examined. The strains were isolated mainly from patients with diarrhea. The majority of the patients declared the consumption of undercooked meat products (especially beef), raw milk and soft cheeses.

\section{Detection of Shiga toxin-producing genes}

The isolates were tested through polymerase chain reaction (PCR) with primers specific for the genes encoding Stx1 and Stx2 toxins (stx1 and stx2 genes).

\subsection{DNA extraction}

The DNA extraction protocol followed the steps previously reported by Lapusan (2012). Briefly, 2-3 presumptive E.coli colonies were chosen and immersed in $150 \mu \mathrm{l}$ Chelex solution (Germany). The Eppendorf tubes were afterwards subjected to high-degree temperatures for cell membrane lysis, releasing the DNA, which was quantified on a Nanodrop ND-1000 spectrophotometer analyzer (NanoDrop Technologies, Inc., Wilmington, DE, USA).

\subsection{The PCR method}

The PCR reaction mix $(25 \mu \mathrm{l})$ comprised: $1 \mathrm{X}$ PCR green Buffer, $2.5 \mathrm{mM} \mathrm{MgCl2}, 5$ pmol of each primer, dNTPs each at $200 \mu \mathrm{M}, 2.5 \mathrm{U}$ of Taq DNA Polymerase (Promega, Madison, WI, USA) and 100 ng of genomic DNA. PCR was performed under the following conditions: $94^{\circ} \mathrm{C}$ for $3 \mathrm{~min}$ followed by 35 cycles of $94^{\circ} \mathrm{C}$ for $30 \mathrm{sec}, 60^{\circ} \mathrm{C}$ for $30 \mathrm{sec}, 72^{\circ} \mathrm{C}$ for $1 \mathrm{~min}$ and a final extension step of $72^{\circ} \mathrm{C}$ for 7 min.

The primers used for the detection of Shiga toxin-producing genes were previously reported by Tahamtan et al. (2010).

\section{Antibiotic susceptibility tests}

A number of 26 antimicrobials, some commonly used in veterinary medicine and some mainly employed in humans, were tested on the E.coli isolates, using the classical disk diffusion method, according to the guidelines of the Clinical and Laboratory Standards Institute (CLSI) (CLSI, 2006). The isolates were tested against ampicillin, cefotaxime, ceftazidime, ciprofloxacin, nalidixic acid, tetracycline, trimethoprim/sulfamethoxazole, amoxicillin and clavulanic acid, chloramphenicol, gentamicin, piperacillin, cefazolin, cefoxitin, cefepime, amikacin, norfloxacin, nitrofurantoin, cefuroxime, tobramycin, cefixime, cefoperazone, imipenem, meropenem, entopenem, levofloxacin and fosfomycin. The CLSI breakpoints were applied for the interpretation of the results. 


\section{RESULTS AND DISCUSSIONS}

A number of 30 E.coli isolates recovered from patients hospitalized with food-borne infections at the Hospital of Infectious Diseases from ClujNapoca, were tested for Shiga toxin-producing genes through PCR and also for antimicrobial susceptibility to 26 antimicrobial agents, some commonly used in veterinary medicine and some mainly employed in humans, by using the classical disk diffusion method.

All isolates included in this study carried Shiga toxin-producing genes. PCR showed that 8 isolates $(26.66 \%)$ carried stx1 genes, $16(53.33 \%)$ carried stx2 genes, while $6(20 \%)$ isolates possessed both stx1 and stx2 genes.

The analyzed E.coli isolates proved to be highly resistant to antimicrobials. All isolates showed resistance to more than one antimicrobial. Overall, resistance was frequently observed to ampicillin (60.66\%), nalidixic acid (56.66\%) and norfloxacin (56.66\%). The E.coli isolates included in the study also displayed resistance to ciprofloxacin, tetracycline, gentamicin, cefuroxime, cefotaxime, ceftazidime, cefixime, nitrofurantoin, trimethoprim/sulfamethoxazole and piperacillin. A lower resistance rate was observed to cefoxitin, amikacin and chloramphenicol. All isolates proved to be susceptible to imipenem, meropenem and entopenem (Tab. 1).

The emergence and dissemination of antimicrobial resistance among Shiga toxin-producing E.coli may have potential negative clinical implications.

The World Health Organization (WHO) published a report regarding the critically important antimicrobials for human medicine. According to the report, third and fourth generation cephalosporins, as well as quinolones and amynoglicosides are considered to be critically important antimicrobials in the treatment of human E.coli infections (World Health Organization, 2007). Moreover, in the case of E.coli, first and second generation cephalosporins as well as sulfonamides are regarded as highly important antimicrobials for the treatment of E.coli infections in humans. According to our study a high percentage of the isolates proved to be highly resistant to third and fourth generation cephalosporins (cefotaxime, ceftazidime, cefepime, cefixime, cefoperazone) and also to quinolo-
Tab. 1. Percentage of E.coli isolates resistant to different antimicrobials

\begin{tabular}{lc}
\hline Antimicrobials & $\begin{array}{c}\text { Percentage of } \\
\text { resistance }\end{array}$ \\
\hline Ampicillin & 60.66 \\
\hline Cefotaxime & 33.33 \\
\hline Ceftazidime & 33.33 \\
\hline Ciprofloxacin & 40 \\
\hline Nalidixic acid & 56.66 \\
\hline Tetracycline & 40 \\
\hline Trimethoprim/ & 33.33 \\
\hline sulfamethoxazole & 50 \\
\hline Amoxicillin and clavulanic acid & 6.66 \\
\hline Chloramphenicol & 40 \\
\hline Pentamicin & 33.33 \\
\hline Cefazolin & 13.33 \\
\hline Cefoxitin & 6.66 \\
\hline Cefepime & 23.33 \\
\hline Amikacin & 6.66 \\
\hline Norfloxacin & 56.66 \\
\hline Nitrofurantoin & 16.66 \\
\hline Cefuroxime & 40 \\
\hline Tobramycin & 23.33 \\
\hline Cefixime & 33.33 \\
\hline Cefoperazone & 23.33 \\
\hline Imipenem & 0 \\
\hline Meropenem & 0 \\
\hline Entopenem & 0 \\
\hline Levofloxacin & 23.3 \\
\hline Fosfomycin & 23.33 \\
\hline & \\
\hline
\end{tabular}

nes (nalidixic acid) and fluoruoquinolones (ciprofloxacin, norfloxacin, levofloxacin).

Fluoroquiolones are critically important for treating serious infections in humans (Van et al., 2008). Treatment of serious human enteric infections with an effective fluoroquinolone can reduce the duration of illness, and most likely prevent complications and adverse outcomes including hospitalization (FDA, 2000). Therefore, resistance to fluoroquinolones can be considered an important public health concern.

A high resistance rate was observed to gentamicine, an amynoglicoside which is also 
included in the list of critically important antimicrobials for human therapy. In humans, gentamicin is used in association with $\beta$-lactams, for the treatment of severe infections like sepsis or endocarditis.

The highest resistance rate was observed to ampicillin, an antibiotic frequently administered in both human and veterinary medicine.

Even if the origin of E.coli that caused the infections has not been properly investigated, it was assumed that it must have been an alimentary one, given the fact that the majority of the patients declared the consumption of undercooked meat products (especially beef), raw milk or soft cheeses.

In many cases, the origin of E.coli that cause infection in humans remains unknown, and the significance of the animal reservoir of the antimicrobial resistant E.coli has not been quantified. However, treatment options in humans are compromised if the causative bacteria are already resistant to commonly used antimicrobial agents (Hammerum and Heuer, 2013).

Moreover, it is a well known fact that foods contaminated with antibiotic resistant bacteria could be a major threat to public health, as there is the distinct possibility that genes encoding antibiotic resistance determinants that are carried on mobile genetic elements may be transferred to other bacteria of human clinical significance (Van et al., 2008). E.coli is a candidate vehicle for such transfer because of its diversity and also because it survives as common flora in the gastrointestinal tracts of both humans and animals. They are sensitive to selection pressure exerted by antibiotic usage and carry genetic mobile elements to achieve such transmission (Van den Bogaard et al., 2000).

The presence of pathogenic and non-pathogenic E.coli isolated from food and food products and resistant to different antimicrobials has been previously reported by many authors (Van et al., 2008; Saenz et al., 2004; Pavithra et al., 2013; Sala et al., 2012; Karadal et al., 2013; Hosseini et al., 2013, Colobatiu et al., 2014).

In a previous study we've analyzed E.coli isolations for antimicrobial resistance genes. The results of the study proved that E.coli isolates recovered from raw poultry meat are highly resistant to antimicrobials and carry antimicrobial resistance genes that could be transferred to other microbes in the food chain, even important human pathogens (Colobatiu et al., 2014).
The isolates included in our study proved to be resistant to a large number of antimicrobial agents, some of them being commonly used in the prophylaxis or treatment of infections in human as well as in veterinary medicine. The widespread non-human use of antimicrobial agents, some of them regarded as critically or highly important for human therapy, creates a reservoir of resistant bacteria or resistance genes that may be transferred to humans, adding to the burden of antimicrobial resistance in human medicine (Hammerum and Heuer, 2013).

\section{CONCLUSIONS}

This study was conducted in order to reveal antimicrobial resistance patterns of E.coli of presumably animal origin, causing human illness.

Our findings demonstrate that Shiga Toxinproducing E.coli, presumably of animal origin and recovered from hospitalized patients, is highly resistant to critically important antimicrobials for human medicine. These data support the ongoing concern regarding antimicrobial resistance, antimicrobial use in veterinary and human medicine and nevertheless, the problem of antimicrobial resistance in the food chain.

Our findings provide a baseline data for further epidemiological studies which lack in information regarding our country.

We underline the necessity of the implementation of a national antimicrobial resistance monitoring programme.

Acknowledgment. This paper was published under the frame of European Social Found, Human Resources Development Operational Programme 2007-2013, projectno. POSDRU/159/1.5/S/136893.

\section{REFERENCES}

1. Alvarez-Fernandez E, Cancelo A, Díaz-Vega C, Capita R, Alonso-Calleja C (2013). Antimicrobial resistance in E. coli isolates from conventionally and organically reared poultry: a comparison of agar disc diffusion and Sensi Test Gram-negative methods. Food Control 30:227-234.

2. Belongia EA, MacDonald KL, Parham GL, White KE, Korlath JA, Lobato MN, et al. (1991). An outbreak of Escherichia coli 0157:H7 colitis associated with consumption of precooked meat patties. J Infect Dis 164:338- 43.

3. CLSI document M2-A9. Wayne, Pa: CLSI. (2006): Clinical Laboratory Standards Institute. Performance standards for antimicrobial disc susceptibility tests. Approved standard. 
4. Colobatiu L, Oniga O, Tabaran A, Mihaiu R, Mirel S, Dan SD, Mihaiu M (2014). An analysis of Escherichia coli isolations for antimicrobial resistance genes. J Food Safety 34(3): 233-238.

5. Costa D, Poeta P, Sa' enz Y, Coelho AC, Matos M, Vinue' $\mathrm{L}$, et al. (2008). Prevalence of antimicrobial resistance and resistance genes in faecal Escherichia coli isolates recovered from healthy pets. Vet. Microbiol 127:97-105.

6. FDA (Food and Drug Administration) (2000). Enrofloxacin for poultry; Opportunity for hearing. Federal Register 65,211,0ctober 31.

7. Hammerum AM, Heuer OE (2009). Human health hazards from antimicrobial-resistant Escherichia coli of animal origin. Clin Infect Dis. 48:916-919.

8. Hosseini H, Jamshidi A, Besssami MR, Zeynali T, Khaneghah AM, Khanzadi S (2013). Isolation, Identification and Virulence Gene Profiling of Escherichia coli 0157:H7 in Retail Doner Kebabs, Iran. J Food Safety 33: 489-496. DOI: $10.1111 /$ jfs. 12080

9. Karadal F, Ertas N, Hizlisoy H, Abay S, Al S (2013). Prevalence of Escherichia coli 0157:H7 and Their Verotoxines and Salmonella spp. in Processed Poultry Products. J Food Safety 33:313-318. DOI: 10.1111/ jfs.12054

10. Lapusan A (2012). Teza de doctorat: "Cercetătări privind markerii de calitate si autenticitate atestati in cadrul trasabilitatii laptelui de bivolita".

11. Mora A, Blanco JE, Blanco M, Alonso MP, Dhabi G, Echelta A, Gonzales EA, Bernardez EI, Blanco J (2005). Antimicrobial resistance of Shiga toxin (verotoxin)producing Escherichia coli 0157:H7 and non-0157 strains isolated from humans, cattle, sheep and food in Spain. Res Microbiol 156(7):793-806.

12. Pavithra M, Ghosh AR (2013). Multidrug-Resistant stx1 Harboring Escherichia coli from Meat Shop and Fast Food. J Food Safety 33:453-460. DOI: 10.1111/jfs.12076

13. Sáenz Y, Briñas L, Domínguez E, Ruiz J, Zarazaga M, Vila J, Torres C (2004). Mechanisms of resistance in multipleantibiotic-resistant Escherichia coli strains of human, animal, and food origins. Antimicrob Agents Chemother 48:3996-4001.

14. Sala C, Morar A, Colibar O, Morvay AA (2012). Antibiotic resistance of gram-negative bacteria isolated from meat surface biofilm. Rom Biotech Lett 17(4):7483-7492.

15. Tahamtan Y, Hayati M, Namavari MM. (2010). Contamination of Sheep Carcasses with Verocytotoxin Producing Escherichia coli During Slaughtering. Transbound Emerg Dis. In press.

16. Van den Bogaard AE, Stobberingh EE (2000). Epidemiology of resistance to antibiotics. Links between animals and humans. Int J Antimicrob Agents 14:327-335.

17. Van TTH, Chin J, Chapman T, Tran LT, Coloe JP (2008). Safety of raw meat and shellfish in Vietnam: An analysis of Escherichia coli isolations for antibiotic resistance and virulence genes. Int J Food Microbiol 124:217-223.

18. World Health Organization (WHO). Critically important antimicrobials for human medicine: categorization for the development of risk management strategies to contain antimicrobial resistance due to nonhuman antimicrobial use. Report of the 2 nd WHO expert meeting (Copenhagen, Denmark). Geneva: WHO, 2007. 